\title{
GINGER EXTRACT (ZINGIBER OFFICINALE) HAS ANTI-CANCER AND ANTI-INFLAMMATORY EFFECTS ON ETHIONINE-INDUCED HEPATOMA RATS
}

\author{
Shafina Hanim Mohd Habib, ${ }^{I}$ Suzana Makpol, ${ }^{I}$ Noor Aini Abdul Hamid, ${ }^{\mathrm{I}}$ Srijit \\ Das, II Wan Zurinah Wan Ngah, ${ }^{\text {I } Y a s m i n ~ A n u m ~ M o h d ~ Y u s o f ~}{ }^{\mathrm{I}}$ \\ doi: 10.1590/S1807-59322008000600017
}

Habib SHM, Makpol S, Hamid NAA, Das S, Ngah WZW, Yusof YAM. Ginger extract (zingiber officinale) has anti-cancer and anti-inflammatory effects on ethionine-induced hepatoma rats. Clinics. 2008;63:807-13.

OBJECTIVE: To evaluate the effect of ginger extract on the expression of NFkB and TNF- $\alpha$ in liver cancer-induced rats. METHODS: Male Wistar rats were randomly divided into 5 groups based on diet: i) control (given normal rat chow), ii) olive oil, iii) ginger extract (100mg/kg body weight), iv) choline-deficient diet $+0.1 \%$ ethionine to induce liver cancer and $\mathrm{v}$ ) choline-deficient diet + ginger extract $(100 \mathrm{mg} / \mathrm{kg}$ body weight). Tissue samples obtained at eight weeks were fixed with formalin and embedded in paraffin wax, followed by immunohistochemistry staining for NFKB and TNF- $\alpha$.

RESULTS: The expression of NFאB was detected in the choline-deficient diet group, with $88.3 \pm 1.83 \%$ of samples showing positive staining, while in the choline-deficient diet supplemented with ginger group, the expression of NFkB was significantly reduced, to $32.35 \pm 1.34 \%(\mathrm{p}<0.05)$. In the choline-deficient diet group, $83.3 \pm 4.52 \%$ of samples showed positive staining of TNF- $\alpha$, which was significantly reduced to $7.94 \pm 1.32 \%(\mathrm{p}<0.05)$ when treated with ginger. There was a significant correlation demonstrated between NFKB and TNF- $\alpha$ in the choline-deficient diet group but not in the choline-deficient diet treated with ginger extract group.

CONCLUSION: In conclusion, ginger extract significantly reduced the elevated expression of NFKB and TNF- $\alpha$ in rats with liver cancer. Ginger may act as an anti-cancer and anti-inflammatory agent by inactivating NFKB through the suppression of the pro-inflammatory TNF- $\alpha$.

KEYWORDS: Inflammatory markers; TNF- $\alpha$; NFאB; Chemopreventive; Ginger.

\section{INTRODUCTION}

Inflammatory disorders such as gastritis, esophagitis, and hepatitis, which are caused not only by infectious agents such as viruses, bacteria and parasites but also by physical and chemical agents like heat, acid, cigarette smoke and foreign bodies, are recognized as risk factors for human cancer., ${ }^{1,2}$ Inflammation is considered to play an important role in the pathophysiology of cancer. However, when inflammation becomes chronic or lasts too long, it can be harmful. The

${ }^{\mathrm{I}}$ Department of Biochemistry, Faculty of Medicine, Universiti Kebangsaan Malaysia Medical Centre - Kuala Lumpur, Malaysia.

II Department of Anatomy, Faculty of Medicine, Universiti Kebangsaan Malaysia Medical Centre - Kuala Lumpur, Malaysia.

Email: anum@medic.ukm.my

Tel.: 6039289.5297

Received for publication on June 10, 2008

Accepted for publication on August 8, 2008 diagnosis of inflammation and its biomarkers are not fully understood; however, pro-inflammatory cytokines, chemokines, adhesion molecules and the inflammatory enzymes have been linked to chronic inflammation. ${ }^{2}$

Chronic inflammation has been found to mediate a wide variety of diseases including cardiovascular diseases, diabetes, arthritis, Alzheimer's disease, pulmonary diseases and autoimmune diseases. Chronic inflammation has also been associated with various steps involved in carcinogenesis as well as cellular transformation, promotion, survival, proliferation, invasion, angiogenesis and metastasis. ${ }^{2-4}$ During the carcinogenesis process, tumor-infiltrating inflammatory cells produce various types of cytokines. It has been proposed that pro-inflammatory cytokines including TNF- $\alpha$, IL $1 \beta$, IL- 6 and interferon- $\gamma$ contribute to carcinogenesis by influencing the survival, growth, mutation, proliferation, differentiation and movement of 
tumor cells. ${ }^{5}$ Many pro-inflammatory cytokines can activate the transcriptional factor $\mathrm{NF} \kappa \mathrm{B}$, while some of the effects of pro-inflammatory cytokines may be mediated through the NFKB pathway. ${ }^{6-8}$

TNF- $\alpha$ is one of the pro-inflammatory cytokines and is a major inducer of NFKB. TNF- $\alpha$ has been implicated in tumor promotion in various experimental models of carcinogenesis. ${ }^{3,8}$ The incidence and multiplicity of papilloma in a two-stage mouse skin carcinogenesis model were found to be lowered in TNF- $\alpha-/-$ animals as compared with mice over-expressing TNF- $\alpha .{ }^{9}$ TNF- $\alpha$, interleukins, COX-2, and other chemokines can also be regulated by the transcriptional factor NFKB. Although this factor is expressed in an inactive state in most cells, cancer cells expressed an activated form of NFKB, which was induced by various inflammatory stimuli and carcinogens. ${ }^{10}$ Many studies have linked the NFKB signaling pathway and its regulation with the inflammatory response. ${ }^{10,11}$ Thus, inhibiting the NFKB signaling pathway might be a therapeutic strategy in conjunction with the usage of chemopreventive agents such as ginger. ${ }^{12,13}$

Ginger has long been used in traditional medicine as a cure for some diseases including inflammatory diseases. ${ }^{14}$ Ginger contains active phenolic compounds such as gingerol, paradol and shogoal that have antioxidant, ${ }^{15}$ anti-cancer, ${ }^{16}$ anti-inflammatory, ${ }^{17}$ anti-angiogenesis ${ }^{18}$ and anti-artherosclerotic properties. ${ }^{19}$ It has also been shown to down-regulate NF- $\kappa \mathrm{B}$-regulated gene products involved in cellular proliferation and angiogenesis, including IL- $8,{ }^{20}$ VEGF $^{21}$ and ovarian cancer cells. ${ }^{22}$

In the present study, we tested the potential antiinflammatory and anti-cancer effects of ginger extract by using an immunohistochemistry technique to detect the presence of the inflammatory marker TNF- $\alpha$ and the transcription factor $\mathrm{NF \kappa B}$ and to observe the correlation between these two factors in liver carcinogenesis.

\section{MATERIALS AND METHODS}

\section{Animals, Chemicals and Treatment}

Male Wistar albino rats aged 3-4 months and weighing 200-250 g were supplied by the Animal Care Unit of Universiti Kebangsaan Malaysia (UKM), Kuala Lumpur, Malaysia. The study was approved by the Animal Ethics of Faculty of Medicine, Faculty of Medicine, UKM. Animals were kept in pairs in polycarbonate cages and provided with food and water ad libitum. They were maintained under standard conditions of temperature and humidity with an alternating light and dark cycle. Rats were randomized into five groups of six animals each. The first group and the second group served as control groups and were fed with normal rat chow (Gold Coin, Malaysia) and olive oil, respectively. The latter served as a control for the gavage method and the delivery of ginger. Rats in group 3 received ginger extract at $100 \mathrm{mg} / \mathrm{kg}$ body weight by the gavage method. Ginger extract was prepared by ethanol extraction and kept at $4^{\circ} \mathrm{C}$. It was dissolved in olive oil and force-fed to the rats. Rats in group 4 were fed with a choline-deficient diet (ICN Biochemicals, USA) plus $0.1 \%$ ethionine (Sigma Chemical Co., USA) in drinking water; this is known as the CDE diet. This is the model to induce the production of oval cells, which are the precursor cells of liver cancer ${ }^{23}$. Rats in group 5 received ginger as in group 3 plus the CDE diet. All rats were killed at eight weeks for the observation of liver tumor incidence, and the liver tissues were excised after perfusion and embedded in paraffin blocks for immunohistochemistry staining.

\section{Liver perfusion and preparation for paraffin blocks}

The rats were sacrificed using ether. All equipments for dissection were sterilized using $70 \%$ alcohol before use. The rats were anesthetized intraperitoneally with Zoletil 50 $(0.1 \mathrm{ml} / 100 \mathrm{~g}$ body weight), followed by heparin $(25,000$ $\mathrm{U} / \mathrm{ml}$ ) injection to the inferior vena cava. The portal vein was then canulated using an intravenous catheter, size 16 $\mathrm{G}$ (2.25 inches) for the perfusion procedure. The liver was

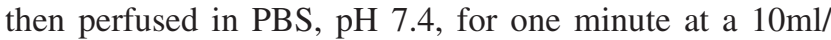
min flow rate at room temperature, followed by $1: 1$ ratio of $4 \%$ paraformaldehyde and $0.1 \%$ glutaraldehyde for three minutes. Then the liver was perfused in PBS for another two minutes. A portion of the perfused liver was then immersed in $10 \%$ formalin for fixation before embedding in paraffin.

\section{Preparation of tissues sections}

The paraffin-embedded tissues were cut $3 \mu \mathrm{m}$ thick with Leica RM2135 rotation microtome (Leica, Germany). The tissue sections were placed on poly-L-Lysine (Sigma-Aldrich Co. USA)-treated slides with 1:10 dilution. The slides were then dried overnight and stored at room temperature until being used for staining.

\section{General protocol for immunohistochemistry staining}

The sections were deparaffinized and hydrated by sequential immersion in xylene, graded alcohol solutions $(100 \%, 95 \%, 80 \%$ and $70 \%)$ for three minutes at each concentration and running water for three minutes. Then sections were incubated in $3 \%$ hydrogen peroxide for $10 \mathrm{~min}$ to block the activity of endogenous peroxidases. Sections 
were washed with TRIS-HCl-buffered saline (TBS) before immersion in Target Retrieval Solution (TRS) (DAKO, U.S.A.) for 20 minutes in a water bath at $98^{\circ} \mathrm{C}$. The TRS solution could be either in high $\mathrm{pH}$, where it ranged from 9.8 to 9.9 or low $\mathrm{pH}$, with a range of 6.0 to 6.2 . The slides with TRS solution were left at room temperature for 20 minutes before being washed with TBS three times for three minutes each. To reduce the background staining, the slides were immersed in Biotin and avidin solution for 30 minutes. The sections were then further blocked with Bovine Serum Albumin (BSA) to reduce the non-specific staining, followed by one hour of incubation with the primary antibody at different concentrations (1:50, 1:100, 1:200, 1: 400, 1:500, $1: 600$ and $1: 1000)$ at room temperature or overnight at $4^{\circ} \mathrm{C}$. The sections were washed three times with TBS for three minutes each before incubating for 30 minutes with the secondary antibody conjugated with biotin and subsequently with Streptavidin-HRP (anti-mouse, anti-rabbit and antirat LSAB + System-HRP kit, DAKO, USA). The sections were washed again with TBS before finally incubating with DAB for 10 minutes. The sections were counterstained with Meyer's Hematoxylin and mounted with DPX for viewing of the slides.

\section{NFKB immunohistochemistry staining}

Cervical cancer tissues obtained from the Department of Pathology, University Kebangsaan Malaysia Medical Center (UKMMC), served as the positive and negative controls. The optimum concentration of the primary antibody (polyclonal rabbit anti-human Nuclear Factor kappa B, Santa Cruz Biotechnology, Inc.) for NFKB was found to be 1:500 for one hour of incubation at room temperature using low $\mathrm{pH}$ Target Retrieval Solution (TRS) (DAKO, USA).

\section{TNF- $\alpha$ immunohistochemistry staining}

Breast cancer tissues obtained from the Department of
Pathology, University Kebangsaan Malaysia Medical Center (UKMMC), served as the positive and negative controls. The optimum concentration of the primary antibody (polyclonal rabbit anti-mouse Tumour Necrosis Factor-alpha, Hycult Biotechnology) for TNF- $\alpha$ was found to be 1:100 for one hour of incubation at room temperature using high $\mathrm{pH}$ Target Retrieval Solution (TRS) (DAKO, USA).

\section{Immunostaining analysis}

Immunoreactivity evaluation was based on percentage of positive staining of NFKB and TNF- $\alpha$. The mean percentage of positive-staining cells was determined by counting 1000 stained cells at 10 different fields observed under $400 \mathrm{X}$ magnification using a light microscope.

\section{Statistical analysis}

Data obtained were analyzed using the SPSS 11.0 program. Results are presented as mean $\pm \mathrm{SD}$. The one-way ANOVA test was used, with $\mathrm{p}<0.05$ regarded as significant. Pearson correlation analysis was carried out to determine the relationship between NFKB and TNF- $\alpha$ in both the CDE and the $\mathrm{CDE}$-treated ginger group.

\section{RESULTS}

\section{Liver tumor incidence and body weights of rats}

Table 1 summarizes the incidence of liver neoplasms in rats on a low lipotrope diet with ethionine in drinking water and the effect of ginger on cancer incidence. There were no liver nodules in either the control groups (normal rat chow and olive oil) or the ginger treated rats. However, in CDE rats the pre-neoplastic nodules incidence was $100 \%$ and the average size of the nodules was $0.5-1 \mathrm{~cm}$. Ginger treatment to $\mathrm{CDE}$ rats lowered the liver nodules incidence to $17 \%$.

Table 2 summarizes the body weights of rats under

Table 1 - Effect of Ginger on the incidence of liver neoplasms in ethionine induced rat hepatocarcinogenesis. The formation of preneoplastic liver nodules was induced in rats by feeding them with a choline-deficient diet supplemented with 0.1 ethionine in drinking water. Ginger extract at $100 \mathrm{mg} / \mathrm{kg}$ body weight (dissolved in olive oil) was force-fed to rats. Rats were killed at eight weeks, as described in the Materials and Method section, for the observation of liver nodules

\begin{tabular}{lcccc}
\hline Group & Number of rats examined & Number of rats with tumors & Incidence of tumor $(\%) * *$ & Tumor size $(\mathrm{cm})$ \\
\hline Control & 6 & 0 & 0 & 0 \\
CDE & 6 & 6 & 100 & 1 \\
Olive oil & 6 & 0 & 0 & 0 \\
Ginger* & 6 & 0 & 0 & 0 \\
Ginger + CDE & 6 & 1 & 17 & 0.1 \\
\hline
\end{tabular}

* $100 \mathrm{mg} / \mathrm{kg}$ body weight; **Calculated by dividing the number of rats with preneoplastic nodules by the total number of rats in the group 
Table 2 - Weight of rats with different diet treatment

\begin{tabular}{lcc}
\hline Diet treatment & Week 0 body wt $(\mathrm{g})$ & Week 8 body wt $(\mathrm{g})^{*}$ \\
\hline Control & $238.11 \pm 5.44$ & $313.73 \pm 7.77$ \\
CDE & $240.21 \pm 2.19$ & $222.41 \pm 4.76$ \\
Olive oil & $239.59 \pm 4.52$ & $300.58 \pm 10.89^{\mathrm{a}}$ \\
Ginger & $239.58 \pm 4.52$ & $303.10 \pm 6.27^{\mathrm{a}}$ \\
$(100 \mathrm{mg} / \mathrm{kg}$ body wt $)$ & & \\
CDE + Ginger & $239.74 \pm 2.23$ & $259.96 \pm 9.09^{\mathrm{a}}$ \\
$(100 \mathrm{mg} / \mathrm{kg}$ body wt $)$ & & \\
\hline
\end{tabular}

Data shows Mean \pm S.D.; $*$ significantly different $(\mathrm{p}<0.001)$ compared to week 0 for the same group

different diet conditions. With the exception of the CDE group, all other groups showed significant elevations of body weight at eight weeks compared with those at the 0 week. However, CDE rats showed reduced body weights due to the carcinogen diet, which had altered the rats' metabolism and reduced their appetite for food.

\section{Oval cells}

Figure 1A shows the normal morphology of hepatocytes, Kupfer cells and sinusoids lining the control group, while Figure 1B showed abnormal morphology of liver tissues in the CDE group with the presence of numerous oval cells (scanty cytoplasm with large nucleus), which are precursors of liver cancer cells.

\section{NFKB staining}

Figure 2a showed positive NFkB staining in the control cervical cancer tissue. Figures $2 b$ and $2 c$ show the control
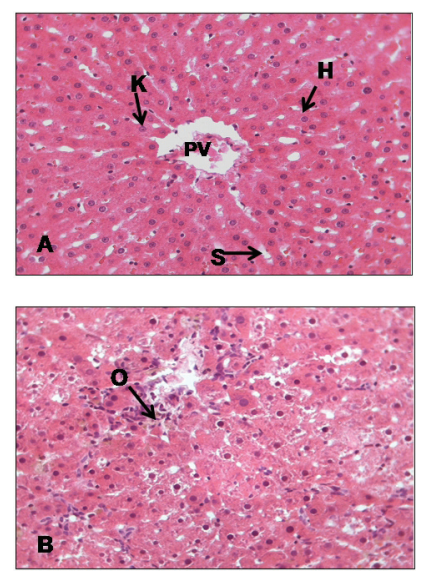

Figure 1 - H \& E staining on liver tissue of (A) control group (given a normal diet) (B) CDE group without treatment of CV (liver cancer was induced with $0.1 \%$ ethionine in drinking water plus a choline-deficient diet). H: Hepatocyte, K: Kuppfer cell, PV: Portal vein, S: Sinusoid, O: Oval cell (magnification $\mathrm{x} 400$ )

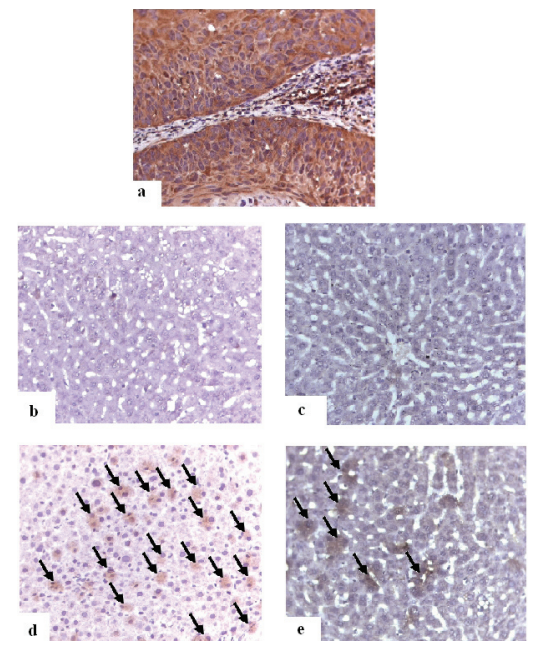

Figure 2 - Immunohistochemical expression of NFkB. (A) Positive NFkB staining in cervical cancer tissue at optimum concentration of 1:500, (B) Control group (C) Ginger extract group, (D) Choline deficient diet with ethionine in drinking water, $\mathrm{CDE}$ group and (E) $\mathrm{CDE}+$ ginger extract (100 $\mathrm{mg} / \mathrm{kg}$ body wt) group. The arrows indicate positive staining of NFkB (400x). OV: oval cells; H: hepatocytes; S: sinosoids; VP; vena portal (x400)

group and the group of rats supplemented with ginger extract. Neither group showed any expression of NFKB. However, the liver cancer-induced group (CDE)(Figure 2d, Figure 3) showed increased expression of NFKB (88.3\%), while the ginger extract-supplemented group showed significantly reduced expression $(32.4 \%, \mathrm{p}<0.05)$ (Figure 2e, Figure 3).

\section{TNF- $\alpha$ staining}

Figure $4 \mathrm{a}$ showed positive staining for TNF- $\alpha$. in the positive control of breast cancer tissue. Figures $4 \mathrm{~b}$ and $4 \mathrm{c}$ show the control group and the group of rats supplemented with ginger extract. Neither group showed any expression of TNF- $\alpha$. However, the liver cancer-induced group (CDE)

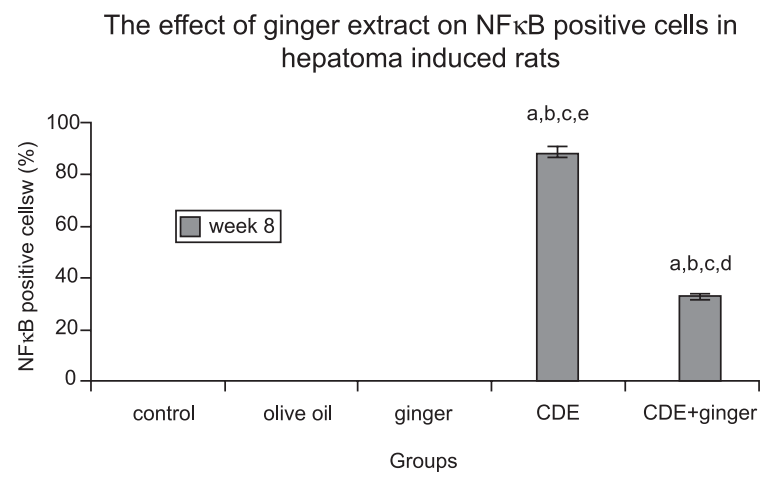

Figure 3 - The effect of ginger extract on NFkB expression in liver cancerinduced rats. The graph shows the positive expression of NFkB based on the different diets given. $\mathrm{A}=\mathrm{p} \leq 0.05$ compared with eight-week control group; $\mathrm{b}=\mathrm{p} \leq 0.05$ compared with olive oil group; $\mathrm{c}=\mathrm{p} \leq 0.05$ compared with ginger group; $\mathrm{d}=\mathrm{p} \leq 0.05$ compared with liver cancer induced group $(\mathrm{CDE}) ; \mathrm{e}=\mathrm{p} \leq 0.05$ compared with $\mathrm{CDE}+$ ginger group 


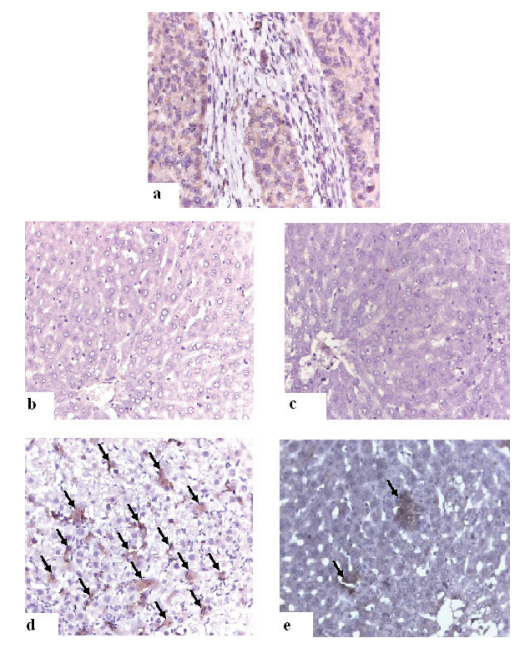

Figure 4 - Immunohistochemical expression of TNF- $\alpha$. (A) Positive control for TNF- $\alpha$ staining in breast cancer tissue at optimum concentration of 1:100; (B) Control group; (C) Ginger extract group; (D) CDE group; and (E) CDE + ginger extract group. The arrows indicate positive staining of TNF- $\alpha(400 \mathrm{x})$. OV: oval cells; H: hepatocytes; S: sinosoids; VP; vena portal

The effect of ginger extract on TNF- $\alpha$ positive cells in hepatoma induced rats

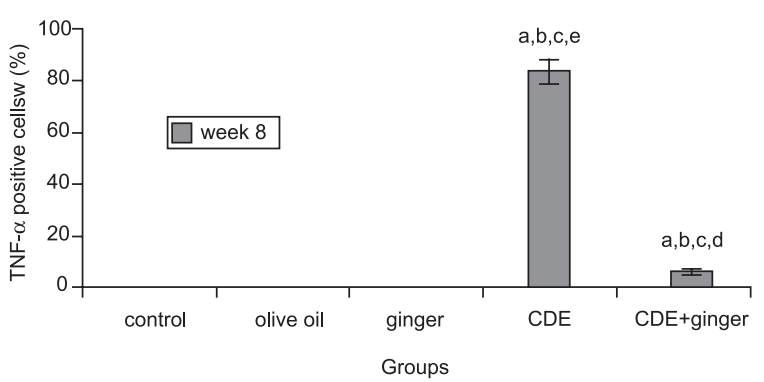

Figure 5 - The effect of ginger extract on TNF- $\alpha$ expression in rats with induced liver cancer. The graph shows the positive expression of TNF- $\alpha$ based on the different diets given. $\mathrm{a}=\mathrm{p} \leq 0.05$ compared with eight-week control group; $\mathrm{b}=\mathrm{p} \leq 0.05$ compared with olive oil group; $\mathrm{c}=\mathrm{p} \leq 0.05$ compared with ginger group; $d=p \leq 0.05$ compared with $\mathrm{CDE}$ group; $\mathrm{e}=\mathrm{p} \leq 0.05$ compared with $\mathrm{CDE}+$ ginger group

(Figure 4d, Figure 5) showed increased expression of TNF- $\alpha$ $(83.3 \%)$, which was reduced significantly $(7.9 \%, \mathrm{p}<0.05)$ with ginger extract supplementation (Figure 4e, Figure 5).

\section{Correlation between TNF- $\alpha$ and NF $\kappa B$ staining}

There was a significant correlation $(\mathrm{r}=0.8776)$ demonstrated between NFKB and TNF- $\alpha$ in the CDE group $(\mathrm{p}<0.01)$ but not in the $\mathrm{CDE}+$ ginger group (Figures $6 \mathrm{a}$ and $6 \mathrm{~b}$, respectively).

\section{DISCUSSION}

There are numerous lines of evidence that suggest that nuclear factor NFKB, a pro-inflammatory transcription
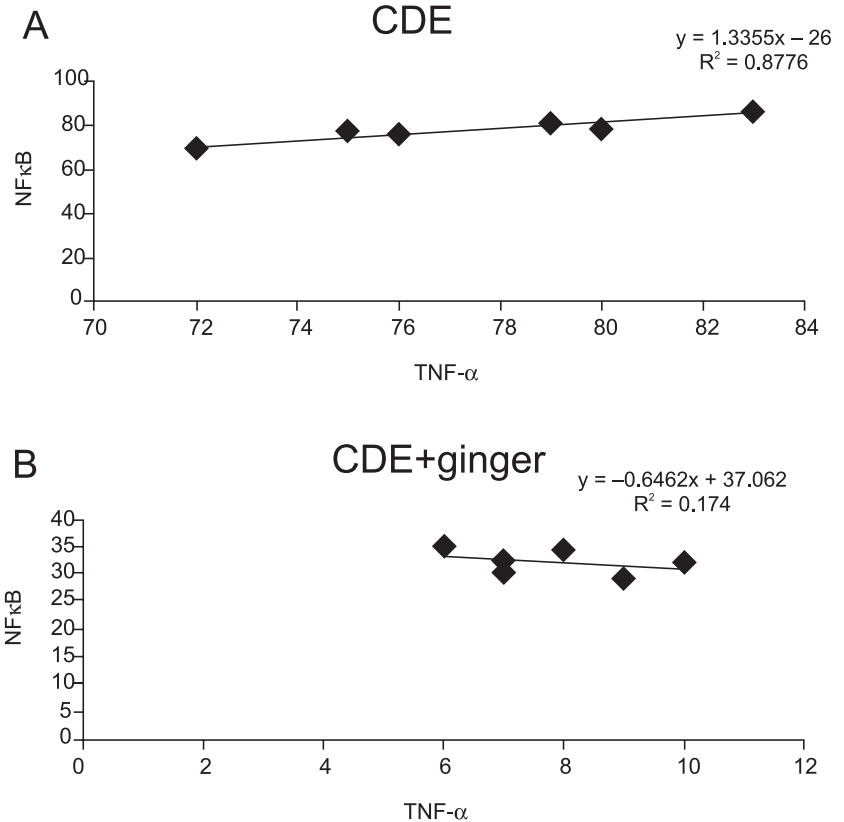

Figure 6 - Correlation coefficient between NFkB and TNF- $\alpha$ expressions in (A) CDE group and in (B) CDE supplemented with ginger extract (100 $\mathrm{mg} / \mathrm{kg}$ body weight) group. Significant correlation was observed between NFkB and TNF- $\alpha$ in CDE group $(r=0.8776, p<0.01)$ but not in the CDE group treated with ginger extract

factor, could promote tumorigenesis after being activated by inflammatory agents, carcinogens and tumor promoters. ${ }^{7}$ It is constitutively active in most tumor cells, and its suppression in these cells leads to inhibition of proliferation, arrest of cell cycle and apoptosis. ${ }^{24}$ In the last few years, work from several groups of researchers provided a causal link between active constitution of $\mathrm{NFKB}$ and liver neoplastic progression. ${ }^{25}$ Hepatocellular carcinoma (HCC) is the fifth most common malignancy in the world and is the third most common cause of cancer-related death worldwide. ${ }^{26}$

Accumulating evidence suggests that many dietary factors may be used alone or in combination with traditional chemotherapeutic agents to prevent or treat cancer. The main advantage of using natural or dietary compounds as an anticancer remedy is that they seem to have low toxicity and show very few adverse side effects. Recently, some plant products have been studied for their possible action as inhibitors of the NFkB pathway. Ginger (Zingiber officinale) is widely used all over the world as a spice and condiment in daily cooking. It is a natural food component with many active phenolic compounds such as shagaol and gingerol, and it has been shown to have anti-cancer and antioxidant effects. ${ }^{12}$ We have shown here that ginger extract was able to reduce the incidence of liver neoplasms in rats; in addition, to our knowledge, this is the first study reporting that the anti-cancer effect exhibited by ginger on liver cancer cells is mediated by inflammatory markers NFKB and TNF- $\alpha$. Oval cell proliferation precedes 
neoplasia in many rodent models of hepatocellular carcinoma, and prevention of this proliferative response can reduce the risk of subsequent carcinoma. ${ }^{23}$

We have shown here that ginger extract was able to block the elevated expression of $\mathrm{NF \kappa B}$ in liver cancer-induced rats. Similarly, elevated expression of TNF- $\alpha$ in liver cancer rats was also blocked when treated with ginger extract $(100 \mathrm{mg} /$ $\mathrm{kg}$ body weight). It is apparent that ginger may act as an anti-cancer and anti-inflammatory agent by blocking the activation of $\mathrm{NFKB}$ via the suppression of pro-inflammatory cytokine, TNF- $\alpha \cdot{ }^{17}$ Other, similar reports have also shown the inhibitory effect of ginger on the NFKB pathway: topical application of 6-gingerol inhibited TPA-induced COX-2 expression and suppressed NFKB DNA binding activity in mice skin. ${ }^{13,27}$ The natural active compounds in ginger (gingerols and zerumbone) have been found to be potent inhibitors for $\mathrm{NFKB}$ and pro-inflammatory cytokine TNF- $\alpha$. Ginger may block any one or more steps in the NFKB signaling pathway, such as the signals that activate the $\mathrm{NF \kappa B}$ signaling cascade, translocation of $\mathrm{NF \kappa B}$ into the nucleus, DNA binding of dimers or interactions with the basal transcriptional machinery. ${ }^{28}$ Inhibiting the activity of NFKB, will subsequently inhibit growth of tumor cells and block metastasis and angiogenesis. The 6-gingerol and 6-paradol have been reported to possess a strong antiinflammatory activity and to suppress the TNF- $\alpha$ production in TPA-treated female ICR-mice and rats. ${ }^{12,27}$

The activation of the TNF- $\alpha$ gene causes the release of pro-inflammatory cytokines, and this would activate the transcriptional factor NFKB. Activation of NFKB would activate the expression of other inflammatory cytokines such as COX-2, LOX-2, other chemokines and iNOS, which would lead to carcinogenesis. ${ }^{29}$ Although no significant correlation between NFKB and TNF- $\alpha$ was found in CDE rats treated with ginger extract, we did show a significant correlation of these two inflammatory markers in rats induced with liver cancer. A possible explanation could be the few samples (12 slides) representing each treatment.

In conclusion, we have shown here that in liver cancer cells, NF- $\mathrm{KB}$ is constitutively activated and that blocking $\mathrm{NF \kappa B}$ activation with ginger resulted in suppressed production of NFKB and TNF- $\alpha$. This is in line with findings that many of the pathways that mediate adaptive survival strategies in cancer cells are under the transcriptional control of NFkB. ${ }^{30}$ Thus, the ginger extract may have a chemotherapeutic effect in the treatment of liver cancer.

\section{ACKNOWLEDGMENTS}

We wish to thank the Department of Biochemistry, Faculty of Medicine, University Kebangsaan Malaysia Medical Centre (UKMMC), for financial support.

\section{REFERENCES}

1. Ohshima H, Bartsc $\mathrm{H}$. Chronic infections and inflammatory processes as cancer risk factors: possible role of nitric oxide in carcinogenesis. Mutat Res. 1994;305: 253-64.

2. Ohshima H, Tatemicho M, Sawa T. Chemical basis of inflammationinduced carcinogenesis. Arch. Biochem Biophys. 2003;417:3-11.

3. Philip M, Rowley DA, Schreiber H. Inflammation as a tumor promoter in cancer induction. Semin Cancer Biol. 2004;14:433-9.

4. Marx J. Inflammation and cancer: the link grows stronger. Science. 2004;306:966-68

5. Lawrence T. Inflammation and cancer: a failure of resolution? Trends in Pharmacol Sci. 2007;28:162-65.

6. Coussens LM, Werb Z. Inflammation and cancer. Nature. 2002;420:86067.

7. Aggarwal BB. Nuclear factor- $\mathrm{BB}$ :The enemy within. Cancer Cell. 2004;6:203-08

8. Aggarwal BB. Signaling pathways of TNF superfamily: a double-edged sword. National Review Immunology. 2003;3:745-56.
9. Balkwill F. Tumor Necrosis Factor or tumor promoting factor? Cytokine Growth Factor Rev. 2002;13:135-41.

10. Lin A, Karin M. NF-kappaB in cancer: a marked target. Semin Cancer Biol. 2003; 13:107-14.

11. Escárcega RO, Fuentes-Alexandro S, García-Carrasco M, Gatica A, Zamora A. The transcription factor kappa B and cancer. Clinical Oncology. (R Coll Radiol) 2007;19:154-61.

12. Surh, YJ. Cancer chemoprevention with dietary phytochemical. Nat Rev Cancer. 2003;3:768-80.

13. Kim SO, Chun KS, Kundu. J, Surh YJ. Inhibitory effects pg 6-gingerol on PMA-induced COX-2 expression and activation of NFKB and p38 MAPK in skin mouse. Biofactors. 2004;21:27-31.

14. Afzal M, Al-Hadidi D, Menon M, Pesek J, Dhami MS. Ginger: an ethnomedical, chemical and pharmacological review. Drug Metabol Drug Interact. 2001;18: 159-90.

15. Jeyakumar SM, Nalini N, Menon VP. Antioxidant activity of ginger (Zingiber officinale) in rats fed a high fat diet. Med Sci Res. 1999;27:34144 
16. Shukla Y, Singh M. Cancer preventive properties of ginger: A brief review. Food Chem Toxicol. 2007;45:683-90.

17. Hudson, E.A., Fox, L.H., Luckett, J.C.A \& Manson, M.M.. Ex vivo cancer chemoprevention research possibilities. Environmental Toxicology and pharmacology. 2006;21:204-14.

18. Huang S, DeGuzman A, Bucana CD, Fidler IJ. Nuclear factor-kappaB activity correlates with growth, angiogenesis, and metastasis of human melanoma cells in nude mice. Clin Cancer Res. 2000;6:2573-81.

19. Coppola G, Novo S. Statins and peripheral arterial disease: effects on claudication, disease progression, and prevention of cardiovascular events. Arch Med Res. 2007;38:479-88.

20. Nonn L, Duong D, Peehl DM: Chemopreventive anti-inflammatory activities of curcumin and other phytochemicals mediated by MAP kinase phosphatase-5 in prostate cells. Carcinogenesis. 2007;28:118896.

21. Kim EC, Min, JK, Kim TY, Lee SJ, Yang HO, Han S, et al. Gingerol, a pungent ingredient of ginger, inhibits angiogenesis in vitro and in vivo Biochem Biophys Res Commun. 2005;335:300-8.

22. Rhode J, Fogoros S, Zick S, Wahl H, Griffith KA, Huang J, et al. Ginger inhibits cell growth and modulates angiogenic factors in ovarian cancer cells. BMC Complementary and Alternative Medicine. 2007;20:7-44.
23. Akhurst B, Croager EJ, Farley-Roche, C.A, Ong JK, Dumble ML, Knight B \& Yeoh GC. 2001. A modified Choline-Deficient, Ethionine Supplemented Diet protocol effectively induces oval cells in mouse liver. Hepatology 34:519-22.

24. Bharti AC, Aggarwal BB. Nuclear factor- $\mathrm{\kappa B}$ and cancer: Its role in prevention and therapy. Biochem Pharmacol. 2002;64:883-88.

25. Arsura M, Cavin LG. Nuclear factor- $\kappa \mathrm{B}$ and liver carcinogenesis. Cancer Lett. 2005;229:157-69.

26. Parkin DM, Bray F, Ferlay J, Pisani P. Estimating the world cancer burden: Globocan 2000. Int J Cancer. 2001;94:153-6.

27. Park KK, Chun KS, Lee SS, Surh YJ. Inhibitory effect of [6] -gingerol, a major pungent principle of ginger, on phorbol ester-induced inflammation, epidermal ornithine decarboxylase activity and skin tumor promotion in ICR mice. Cancer Lett. 1998;129:139-44.

28. Aggarwal BB, Shishodia S. Molecular targets of dietary for prevention and therapy of cancer. Biochem Pharmacol. 2006;71:1397-21.

29. Kundu JK, Surh YJ. Breaking the relay in deregulated cellular signal transduction as a rationale for chemoprevention with anti-inflammatory phytochemicals. Mutat Research. 2005;591:123-46.

30. Padifico F, Leornadi A. NF-kappaB in solid tumors. Biochem Pharmacol. 2006; 72:1142-52. 